\title{
Miracetyma kawa SP. NOV. (COPEPODA, POECILOSTOMATOIDA, ERGASILIDAE) DOS PEIXES DE ÁGUA DOCE DA AMAZÔNIA BRASILEIRA.
}

\author{
José Celso O. MALTA'
}

RESUMO - Miracetyma kawa sp. nov, é proposta. Os espécimens foram coletados dos filamentos branquiais de Rhaphiodon vulpinus Agassiz, 1829. A espécie nova difere da espécietipo $M$. etimaruya no tamanho do corpo, no formato do cefalotórax, por apresentar extensões cuticulares somente nas margens interna e externa distais do terceiro segmento da antena e no formato e ornamentação dos ramos das pernas.

Palavras-chave: Copepoda, Poecilostomatoida, Ergasilidae, Parasitas de Peixes, Amazônia.

Miracetyma kawa sp. nov. (Copepoda, Poecilostomatoida, Ergasilidae) from Freshwater Fishes of the Brazilian Amazon.

ABSTRACT - Miracetyma kawa sp. nov. is proposed. The specimens were collected from the gill filaments of Rhaphiodum vulpinun Agassiz, 1829. The new species differs from the type-species, $M$. etimaruya in size and in the shape of the cephalothorax. Also, the cuticular extensions of the third antennal segment are limited to the internal and external distal margins and the rami of the legs have different shapes and armature.

Key-words: Copepoda, Poecilostomatoida, Ergasilidae, Parasites of Fishes, Amazônia.

\section{INTRODUÇÃO}

A familia Ergasilidae é formada por mais de 150 espécies, parasita peixes teleósteos marinhos, de água doce e moluscos bivalves marinhos. $\mathrm{Os}$ gêneros incluídos nesta familia são: Ergasilus Nordmann, 1832; Thersitina Norman, 1905; Pseudergasilus Yamaguti, 1936; Paraergasilus Markewitsch, 1937, Ostrincola Wilson, 1944; Paeonodes Wilson, 1944; Sinergasilus Yin, 1949; Teredophilus Rancurel, 1954; Neoergasilus Yin, 1956; Nipergasilus Yin, 1956; Mugilicola Tripathi, 1960; Acusicola Cressey, 1970; Abergasilus Hewitt, 1978; Diergasilus Do, 1981:
Dermoergasilus Ho \& Do, 1982; Brasergasilus Thatcher \& Boeger, 1983; Amplexibranchius Thatcher \& Paredes, 1985; Rhinergasilus Boeger \& Thatcher, 1988; Prehendorastrus Boeger \& Thatcher, 1990 e Miracetyma Malta, 1992 (WILSON, 1944; YAMAGUTI, 1963; HEWITT, 1978; KABATA, 1979; HO \& DO, 1982; THATCHER \& PAREDES, 1985; BOEGER \& THATCHER, 1990; MALTA, 1992a, b).

Destes 20 gêneros, sete ocorrem na Região Neotropical: Ergasilus, Acusicola, Brasergasilus, Amplexibranchius, Rhinergasilus, Prehendorastrus e Miracetyma, Com exceção de Ergasilus e Acusicola,

1 Instituto Nacional de Pesquisas da Amazônia. Coordenação de Pesquisas em Biologia Aquática. Caixa Postal 478, 69011-970 - Manaus, Amazonas, Brasil. 
todos os demais são de espécies descritas da Região Amazônica (THATCHER, 1991; MALTA, 1992b).

Os gêneros neotropicais são caracterizados principalmente por modificações na antena e nas pernas. A subfamilia Acusicolinae, com os gêneros Acusicola, Amplexibranchius e Miracetyma caracteriza-se por possuir anatenas que envolvem o filamento branquial e através de um sistema de encaixes nos segmentos terminais, travam o sistema, semelhante a um trinco. Com antenas mais eficientes na fixação, as pernas são menos requisitadas na natação, setas plumadas dão lugar a setas pectinadas e a morfologia se modifica de acordo com as necessidades (THATCHER, 1984, 1991; THATCHER \& PAREDES, 1985; MALTA, 1992a; b).

No gênero Miracetyma o primeiro par de endopoditos perde totalmente as setas, o primeiro segmento torna-se robusto e longo e o segundo fino e alongado. Com estas estruturas, semelhantes a longas pinças, nos leva a crer, que o individuo está mais apto a pegar o alimento e levá-lo até a boca, em um processo mais elaborado e eficiente que qualquer outro grupo dentro de Poecilostomatoida (MALTA, 1992a; b)

\section{MATERIAL E MÉTODOS}

O material foi coletado no Estado de Rondônia, noroeste do Brasil, durante o período de 28 de novembro de 1983 a 25 de setembro 1985 .

Para a captura dos peixes foram utilizadas malhadeiras (redes de espe- ra) padronizadas, com o comprimento variando de 15 a $40 \mathrm{~m}$, a altura de um a três metros e o tamanho das malhas entre 30 e $140 \mathrm{~mm}$ (a distância internós opostos e esticados). Cada estação foi amostrada durante 24 horas e as despescas foram feitas de seis em seis horas.

Os peixes foram identificados, pesados e medidos, comprimento "fork". As brânquias e vísceras foram removidas e fixadas em formol a $10 \%$.

Os copépodos foram retirados dos filamentos branquiais utilizandose finos estiletes e microscópio estereoscópio e fixados em formol a $5 \%$. Lâminas permanentes, com montagem total dos copépodos, foram preparadas usando o método de Thatcher, denominado "HYP". Cada indivíduo foi retirado da solução aquosa (formol a $5 \%$ ) e mantidos em álcool a $70 \%$ no minimo, por cinco minutos. A seguir, colocados em solução corante (partes iguais dos corantes Eosina e Orange$\mathrm{G}$ dissolvidos em álcool a $95 \%$ ), durante três a 10 minutos. Posteriormente os animais foram colocados em fenol puro (cristais de fenol liquefeitos em álcool a 95\%) para diafanizar, desidratar e descolorir o excesso. Em seguida foram colocados em salicilato de metila, para interromper o processo de descoloração. Finalmente, depois de no mínimo três minutos, os copépodos foram montados em bálsamo do Canadá entre lâmina e lamínula e colocados em estufa à $70^{\circ} \mathrm{C}$.

Os desenhos e medidas foram feitos com o auxílio de uma "câmara clara" e uma ocular micrométrica, 
acopladas a um microscópio óptico. Todas as medidas estão expressas em micrômetros.

Os peixes foram depositados na Coleção Ictiológica do Instituto Nacional de Pesquisas da Amazônia, em Manaus.

Os tipos foram depositados nas coleções do Instituto Nacional de Pesquisas da Amazônia (INPA-CR), Manaus, Amazonas e Museu de Zoologia da Universidade de São Paulo, (MZUSP), São Paulo.

\section{RESULTADOS}

\section{Material examinado:}

Holótipo: fêmea (INPA-CR 603), dos filamentos branquiais de Rhapiodum vulpinus, coletado no Rio Mamoré, próximo a Surpresa (11 $\left.{ }^{\circ} 52^{\prime} \mathrm{S} ; 6^{\circ} 56^{\prime} \mathrm{W}\right)$ 25.ix.1985, em lâmina. Parátipos: 8 fêmeas (INPACR 604a - h) e 2 fêmeas (MZUSP 10439a e b) em lâmina; 37 fềmeas (INPA-CR 605) e 5 fêmeas (MZUSP 10438) em formol 5\%; dos filamentos branquiais de Rhapiodon vulpinus: 26 espécimens de 3 peixes da localidade tipo, 24.ix.1985; 10 espécimens de 1 peixe do rio Mamoré, próximo à Guajará-Mirim (1040'S; $\left.65^{\circ} 14^{\prime} \mathrm{W}\right)$, 28.xi. 1983; 1 espécimen de 1 peixe (3 examinados) do rio Guaporé próximo à Pimenteiras $\left(13^{\circ} 28^{\prime} \mathrm{S} ; 61^{\circ} 4^{\prime} \mathrm{W}\right)$, 28.xi.1984; 5 espécimens de 3 peixes (7 examinados) do rio Jamari próximo à Hidrelétrica de Samuel $\left(8^{\circ} 45^{\prime} \mathrm{S}\right.$; $\left.63^{\circ} 26^{\prime} \mathrm{W}\right), 8$ xii. 1984 . Todos coletados por J.C.O. Malta.

Fêmea:
Corpo (Fig. 1 e Tab. 1) alongado, robusto. Comprimento total (8451432). Prossoma mais largo que o urossoma, com a maior largura do corpo ocorrendo no cefalotórax ao nível da região oral.

Cefalotórax (Fig. 1 e Tab. 1) de forma arredondada, muito desenvolvido, região mediana muito larga, medindo cerca de 3,5 vezes mais que a região anterior; cefalossomo fusionado com o segundo somito torácico. Tórax (Fig. 1 e Tab. 1) com 4 somitos livres, de forma retangular e diminuindo progressivamente de tamanho e largura do somito III para o VI. Alguns grânulos de pigmentação púrpura esparsos no cefalotórax e tórax.

Somito genital duplo (Figs. 1-2 e Tab 1) hexagonal com a largura máxima ocorrendo na região mediana.

Abdômen (Figs. 1-3 e Tab. 1) formado por 3 somitos livres e os ramos caudais. Somitos 1 e 2 do abdômen sem ornamentações. Somito 2 (Figs. 1 e 2) com a margem posterior dorsal arredondada e avançando sua área central sobre o próximo somito. Somito 3 (Fig. 3) com uma série de pequenos espinhos na margem posterior ventral. Ramos caudais (Figs. 13) retangulares, ambos equipados com uma seta longa e uma curta, duas setas reduzidas apicais e uma fileira de pequenos espinhos na margem posterior ventral.

Antênula (Fig. 4 e Tab. 2) reduzi$\mathrm{da}$, com cinco segmentos, setas simples e com a fórmula setal: $10-3-1-2$ 5. Tipologia, comprimentos relativos e ornamentações diretamente compará- 


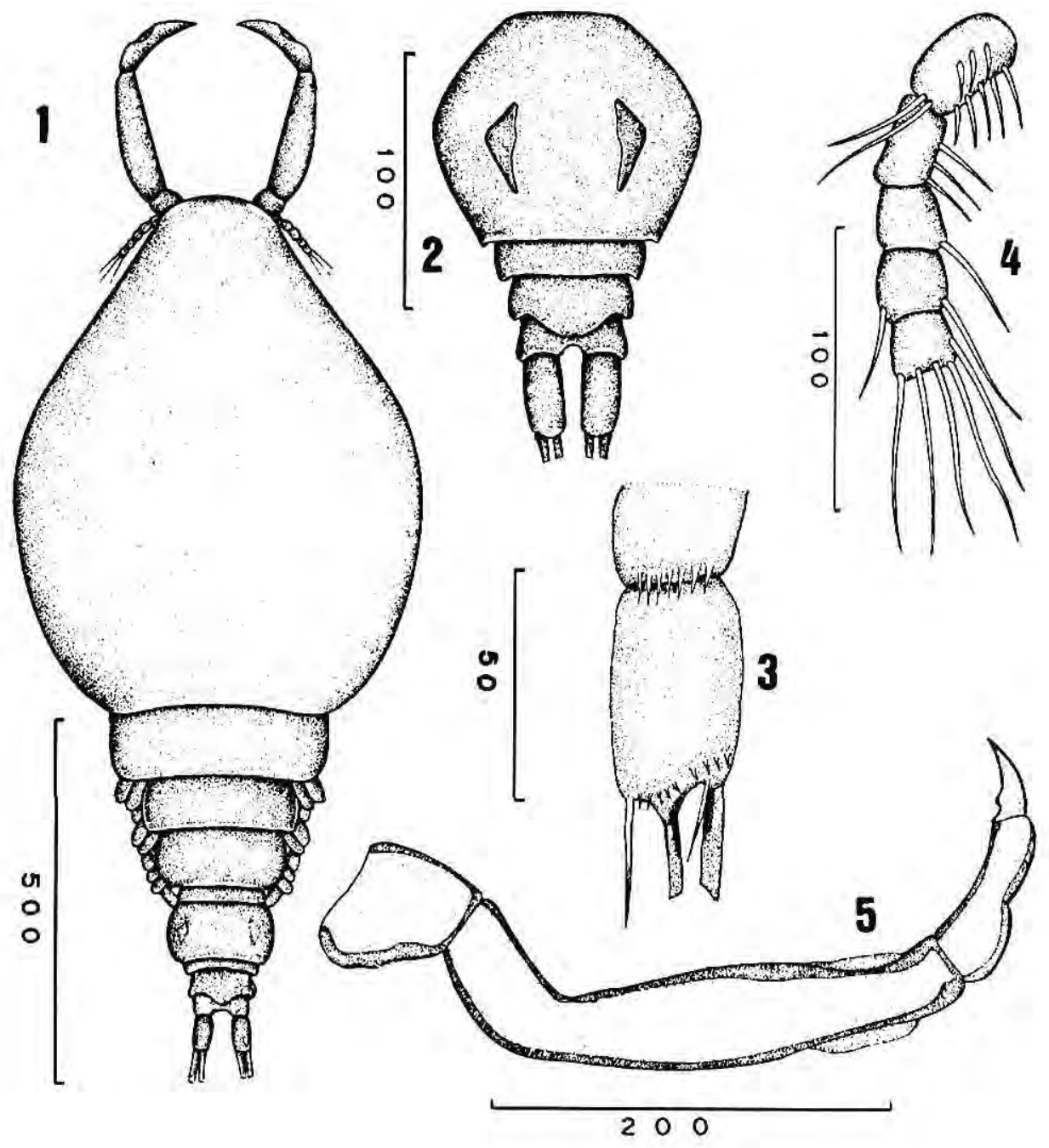

Figuras 1-5. Miracetyma kawa sp. n. (fếmea) 1 - vista dorsal. 2 - somito genital duplo. abdômen e ramos caudais. 3 - ramo caudal (vista ventral). 4 - antênula. 5 - antena. 
Tabela 1. Medidas (variação e média em $\mu \mathrm{m}$ ) de 10 fềmeas adultas de Miracetyma kawa sp. $\mathrm{n}$.

\begin{tabular}{lll}
\hline & \multicolumn{1}{c}{ Comprimento } & \multicolumn{1}{c}{ Largura } \\
\hline $\begin{array}{l}\text { Corpo } \\
\text { Cefalotórax }\end{array}$ & $845-1432(1087)$ & $357-546(467)$ \\
Somitos I e II & $699-468(620)$ & $357-546(467)$ \\
Somitos torácicos & & \\
III & $70-105(88)$ & $202-262(223)$ \\
IV & $65-85(71)$ & $150-177(165)$ \\
V & $50-72(60)$ & $120-137(128)$ \\
VI & $25-37(28)$ & $70-87(78)$ \\
Somito genital duplo & & \\
VII & $82-125(105)$ & $90-125(115)$ \\
Somitos abdominais & & \\
VIII & $15-20(16)$ & $55-77(70)$ \\
IX & $12-22(15)$ & $52-70(63)$ \\
X & $15-25(19)$ & $45-72(60)$ \\
Ramos caudais & & $37-57(48)$ \\
XI & $37-52(40)$ & $81-196(109)$ \\
Saco de ovos & $330-989(604)$ &
\end{tabular}

veis com a espécie-tipo. Antena (Fig. 5 e Tab. 2) sem ornamentações, com a característica garra extremamente reduzida, ranhura, extensões cuticulares características do gênero e com três segmentos. $\mathrm{O}$ primeiro segmento é curto; o segundo muito longo e com uma extensão cuticular na margem interna e externa distal; terceiro segmento comum a ranhura na porção mediana da margem externa. Garra pequena, com uma ranhura bem definida na margem interna. Relação entre os segmentos: $2,0: 7,9: 3,1: 1,0$.

Peças bucais (Fig. 6): mandíbula longa com uma base sub-retangular robusta, próximo ao centro uma protuberância na margem anterior mediana e afilando-se distalmente; lâmina falciforme com dentículos longos na margem posterior e reforço quitinoso na margem anterior; na margem posterior do apêndice longo um palpo pequeno com uma protuberância pequena na margem anterior e uma série de dentículos na margem posterior. Maxílula muito pequena, em forma de placa, região anterior mais larga e sem ornamentações. Maxila com uma base robusta e afilando-se, processo distal falciforme com setas espiniformes circundando as margens na região anterior.

Pernas (Figs. 7-10 e Tab. 3) providas de setas pectinadas; todos os endopoditos mais longos que os exopoditos; ausência de espinhos em todos os segmentos das pernas, exceto o terceiro segmento do primeiro exopodito. Perna I (Fig. 7) endopodito com dois segmentos e exopodito com três. Endopodito extremamente modificado, muito 


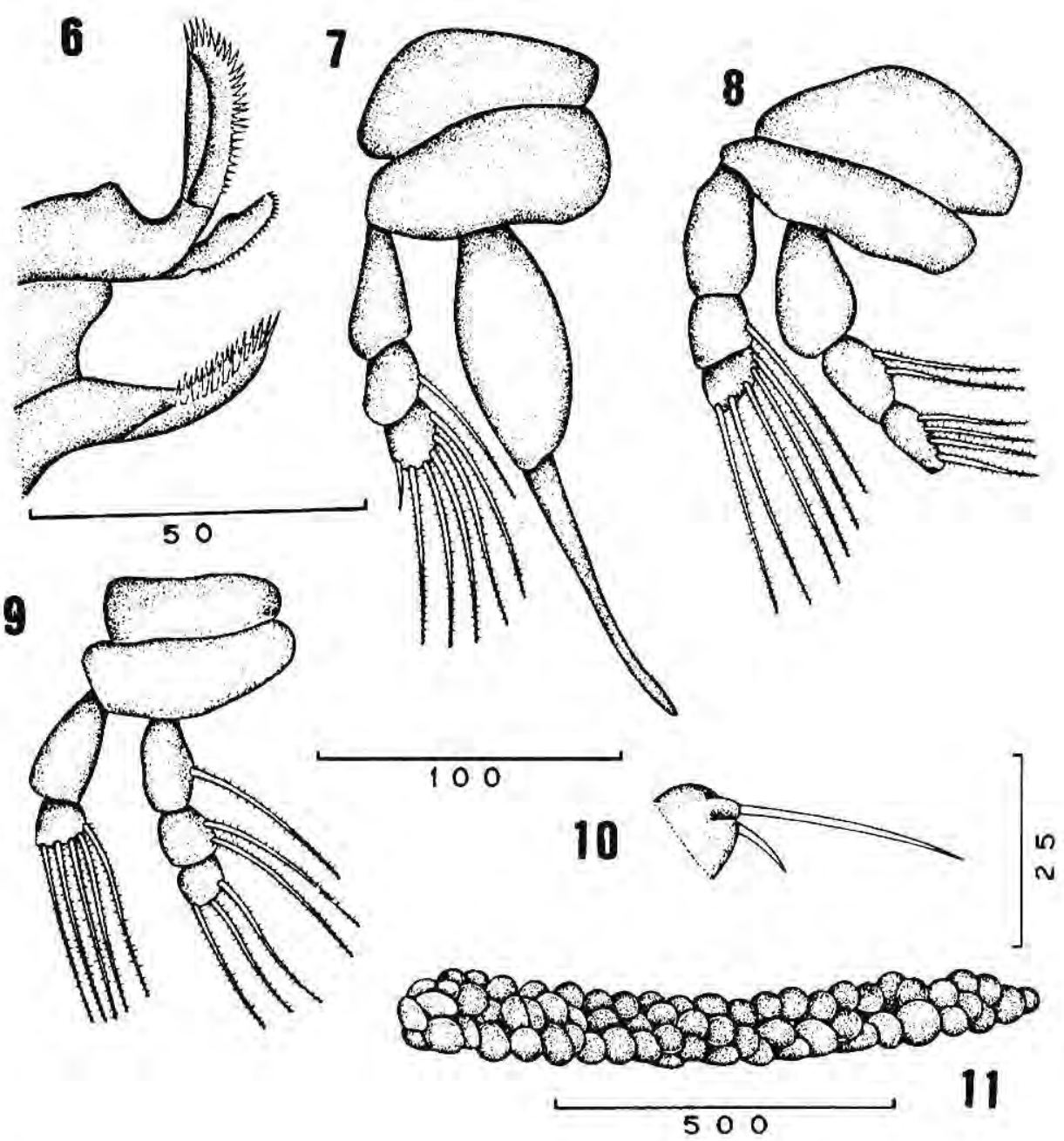

Figuras 6-11. Miracetima kawa sp. 11. (fềmea). 6 - peças bucais. 7 - penna I. 8 - pena II (= perna III). 9 - perna IV. 10 - perna V. 11 - saco de ovos. 
Tabela 2. Medidas das antenas (variação e média em $\mu \mathrm{m}$ ) de 10 fềmeas adultas de Miracetyma kawa sp, n.

\begin{tabular}{llll}
\hline & \multicolumn{1}{c}{ Comprimento } & \multicolumn{1}{c}{ Largura } \\
\hline $\begin{array}{l}\text { Antênula (antena I) } \\
\text { Antena (antena II) }\end{array}$ & $112-150(136)$ & $15-32(25)$ \\
Segmento $\quad 1$ & & \\
& 2 & $65-100(81)$ & $52-70(64)$ \\
& 3 & $272-325(300)$ & $32-45(37)$ \\
& Garra & $90-129(122)$ & $25-30(28)$ \\
\hline
\end{tabular}

grande e sem ornamentações; o primeiro segmento é robusto, comprido e do mesmo comprimento do exopodito, mas 2,2 vezes mais largo; o segundo é longo e fino, 1,2 vezes mais comprido e 2,0 vezes mais estreito que o exopodito. Primeiro segmento do exopodito sem ornamentações, estreito proximal e largo na parte distal, o segundo com uma seta lateral mediana; o terceiro com cinco setas e um espinho. Perna II (Fig. 8) semelhante a perna III com ambos os ramos de três segmentos. Primeiro segmento do endopodito sem ornamentações, mas robusto, largo e de forma subovóide; o segundo com duas setas laterais reduzidas; o terceiro com quatro setas laterais mais reduzidas e a margem distal reta. Primeiro segmento do exopodito sem ornamentações, mas também robusto, largo e de forma sub-retangular; o segundo com uma seta lateral; o terceiro com cinco setas apicais. Perna IV (Fig. 9) endopodito com três segmentos e exopodito com dois. Primeiro segmento do endopodito com uma seta lateral; o segundo com duas; o terceiro com três setas apicais. Primeiro segmento do exopodito sem ornamentações e de forma subretangular; o segundo com cinco setas apicais. Perna V (Fig. 10) vestigial, consistindo de uma seta curta simples e uma longa que se originam em uma papila.

Saco de ovos (Fig. 11) alongado, ovos arranjados em três e quatro séries que variam numericamente, de 12 a 50.

Macho: desconhecido.

Etimologia: 0 nome específico deriva do Tupi-Guarani "kawa", que significa gordo. A forma do cefalotórax dilatada, arredondada, lembra uma pessoa "gorda", volumosa.

\section{DISCUSSÃO}

Miracetyma kawa sp. n. é a segunda espécie do gênero descrita por MALTA (1992b). Foi incluída neste gênero por apresentar o mesmo sistema de trava da antena de $M$. etimaruya e o tamanho e forma do primeiro endopodito semelhantes.

$M$. kawa sp. n. difere de $M$. etimaruya por apresentar todas as medidas do corpo maiores que as de $M$. etimaruya, tanto comprimento quanto largura; antênulas e antenas maiores; formato do cefalotórax arredondado (na espécie-tipo é hexagonal), lembrando ligeiramente o gênero Thersitina Norman, 1905. 
A antena de $M$. kawa apresenta uma extensão cuticular na margem interna e externa distal do segundo segmento, enquanto em $M$. etimaruya estas extensões ocorrem no primeiro e segundo segmentos.

A maxila de $M$. kawa não apresenta ornamentações, enquanto $M$. etimaruya apresenta uma cerda. $\operatorname{Em} M$. kawa, apenas o terceiro segmento do primeiro exopodito tem um espinho, todos os demais segmentos das pernas são desprovidos de espinhos. $\operatorname{Em} M$. etimaruya há uma fileira de pequenos espinhos nas margens externas dos três segmentos do primeiro exopodito, do segundo, do terceiro e do quarto endopoditos e na parte distal externa do primeiro endopodito; um espinho no terceiro segmento do primeiro exopodito, do segundo e do terceiro e dois no segmento terminal do quarto endopodito.

O formato dos segmentos das pernas varia de uma espécie para outra. O primeiro segmento do primeiro endopodito em $M$. kawa é subovóide enquanto que em $M$. etimaruya é subretangular. $\mathrm{O}$ segundo e terceiro endopoditos em $M$. kawa apresentam o primeiro segmento robusto e subovóide e sem setas, as setas do segundo e terceiro segmentos reduzidas. Em $M$. etimaruya o segundo e terceiro endopoditos apresentam o primeiro segmento mais estreito e com uma seta pectinada e setas não reduzidas no segundo e terceiro segmentos.

O número de ovos em $M$. kawa é muito maior variando de 12-50, arranjados em três e quatro séries no saco,
Tabela 3. Espinhos (algarismos romanos) e setas (algarismos arábicos) das pernas de Miracetyma kawa sp. $\mathrm{n}$.

\begin{tabular}{lll}
\hline & \multicolumn{1}{c}{ Exopodito } & Endopodito \\
\hline Perna I & $0-0,0-1,1-5$ & $0-0,0-0$ \\
Perna II & $0-0,0-1,0-5$ & $0-0,0-2,0-4$ \\
Perna III & $0-0,0-1,0-5$ & $0-0,0-2,0-4$ \\
Perna IV & $0-0,0-5$ & $0-1,0-2,0-3$ \\
\hline
\end{tabular}

enquanto que em $M$. etimaruya varia de 15-25, arranjados em duas séries.

Os índices que estimam o tamanho da população de $M$. kawa são: prevalência $60,0 \%$; intensidade variando entre 1-34 copépodos por peixe; intensidade média 9,0 e abundância 6,0 .

\section{Bibliografia Citada}

BOEGER, V. A.; THATCHER, V. E. 1990. Prehendorastrus n. g. (Poecilostomatoida, Ergasilidae) with descriptions of two new species from the rakers of Hypophthalmus spp. (Teleostei, Siluriformes) from the Brazilian Amazon. Syst. Parasitol., 17: 133-141.

HEWITT, G. G. 1978. Abergasilus amplexus gen. et sp. nov. (Ergasilidae: parasitic Copepoda) from fishes in Lake Ellesmere, New Zealand. New Zealand Jour. Mar. Fresh. Reseatch., 12(2): $173-$ 177.

HO, J. S.; DO, T. T. 1982. Two species of Engasilidae (Copepoda: Poecilostomatoida) parasitic on the gills of Mugil cephalus Linnaeus (Pisces, Teleostei), with proposition of a new genus Dermoergasilus. Hydrobiologia, 89:247-252.

KABATA, Z, 1979. Parasitic Copepoda of British Fishes. London: Ray Society, $667 \mathrm{p}$.

MALTA, J. C. O. 1992a. Copépodos (Crustacea: Ergasilidae) das brânquias de peixes do sudoeste da Amazônia Brasileira (Rondônia). Tese de Doutorado, Instituto de Biociências, Universidade Estadual Paulista, Rio Claro, São Paulo, 17lp. 
1992b. Miracetyma etimaruya gen. et sp. noy. (Copepoda, Poecilostomatoida, Ergasilidae) from freshwater fishes of the Brazilian Amazon. Acta Amazonica, $23(1): 49 \cdot 57$.

THATCHER, V. E. 1984. The parasitic crustaceans of fishes from the Brazilian Amazon. 7. Acusicola tucunarense, $\mathrm{n}$. sp. (Copepoda: Ciclopoidea) from Cichla ocelaris, with emendation of the genus and the proposal of Acusicolinae subfam. nov. Rev: Bras. Biol., 44 (2): 181-189.

1991. Amazon Fish Parasites. Amazoniana, 11(3/4): 263-572.
THATCHER, V. E; PAREDES, V. 1985. A parasitic copepod, Anplexibranchis bryconis gen. et sp. nov. (Ergasilidae: Acusicolinae) from an Amazonian fish and remarks on the importance of leg morphology in this subfamily. Amazoniana, 9(2):205-214.

WILSON, C. B. 1944. Parasitic copepods in the United States National Museum. Proc. U. S. Nat. Nat. Mus., 94 (3177): 529-583.

YAMAGUTI, S 1963 Parasitic Copepoda and Branchitura of Fishes. Intersei. Publ: N.Y: $1104 \mathrm{p}$. 